\title{
HIPERPARTICULARIZAÇÃO DE CONCEITOS, NEGACIONISMO CIENTÍFICO E NATUREZA DA CIÊNCIA
}

UMA ANÁLISE DE RESPOSTAS A TEXTOS DE DIVULGAÇÃO

\section{HYPERPARTICULARIZATION OF CONCEPTS, SCIENTIFIC NEGATISM AND THE NATURE OF SCIENCE}

an analysis of responses to scientific dissemination texts

\section{HIPERPARTICULARIZACIÓN DE CONCEPTOS, NEGATISMO CIETÍFICO Y NATURALEZA DE LA CIENCIA}

un análisis de respuestas a textos de divulgación científica

Gildo Girotto Júnior

(Universidade Estadual de Campinas) ggirotto@unicamp.br

Cyntia Almeida Vasconcelos

(Universidade Estadual de Campinas)

cyntia.almeida@gmail.com

Gabriela Fasolo Pivaro

(Universidade Estadual de Campinas) gabifasolo@gmail.com

Recibido: $11 / 01 / 2022$

Aprobado: 14/01/2022

\section{RESUMEN}

Este trabajo buscó analizar, a la luz de las referencias sobre hiperparticularización de conceptos, tipos de negacionismo y Naturaleza de la Ciencia, discursos contrarios a los materiales de divulgación científica producidos en el período de la pandemia de la COVID19. En el análisis, interpretamos el material disponible en forma de comentarios de libre acceso, realizados por lectores de un canal de difusión, con el objetivo de comprender qué características pueden ser identificadas y, con ello, tejer caminos para pensar la educación científica. Es posible identificar categorías que muestran la presencia de aspectos referentes a los tres conceptos utilizados y también hacer consideraciones sobre cómo se relacionan. Además de deconstruir los comentarios, el análisis puede apoyar la planificación de acciones dirigidas a la educación científica y la mitigación de la difusión de información errónea.

Palabras clave: hiperparticularización. negacionismo científico. naturaleza de la ciencia. divulgación científica 


\section{ABSTRACT}

In the light of the references on hyper-particularization of concepts, types of denialism, and Nature of Science, this work sought to analyze discourses contrary to scientific dissemination materials produced in the period of the COVID-19 pandemic. The comments analyzed were written by readers in response to materials produced in an outreach project. We sought to understand which characteristics can be identified and, with that, weave paths for thinking about science education. It is possible to identify categories that evidence the presence of aspects associated with the three references used and to make considerations about how they are related. In addition to deconstructing the comments, the analysis can support the planning of actions aimed at scientific education and the mitigation of the spread of misinformation.

Keywords: hyperparticularization. scientific negativism. nature of science. scientific dissemination.

\section{RESUMO}

Este trabalho buscou analisar, com base em estudos sobre hiperparticularização dos conceitos, tipos de negacionismo e natureza da Ciência, discursos contrários a materiais de divulgação científica produzidos no período da pandemia de COVID-19. Na análise, interpretamos o material - disponível na forma de comentários de acesso livre, feitos por leitores de um canal de divulgação - com o objetivo de identificar características desses discursos e, com isso, poder tecer caminhos para o (re)pensar a educação científica. Assim, foi possível identificar categorias que evidenciam a presença dos aspectos referentes aos três conceitos referidos e, ainda, tecer considerações sobre como eles se relacionam. Além da desconstrução dos comentários, a análise pode subsidiar o planejamento de ações voltadas à educação científica e à mitigação da propagação de desinformação.

Palavras-chave: hiperparticularização. negacionismo científico. natureza da ciência. divulgação científica.

\section{Introdução}

Ações vinculadas ao negacionismo científico e à circulação de informações falsas não são recentes, do ponto de vista histórico. No entanto, com o maior acesso a canais de compartilhamento de informações, elas vêm apresentando um crescimento acelerado (Leite, 2014; Reusing, L.; Wachowicz, 2019). O negacionismo climático, ou mesmo a confusão promovida pela indústria do tabaco nas décadas de 80 e 90, são exemplos temporalmente próximos que ilustram mecanismos utilizados pelos atores envolvidos nessas ações.

Ao longo dos anos de 2020 e 2021, no contexto da pandemia de COVID-19, fontes de desinformação emergiram incessantemente; e inúmeras Fake News foram propagadas, envolvendo diferentes temas. Simultaneamente, e como tentativa de resposta, agências de checagem de informações e grupos de divulgação científica compostos por profissionais de diferentes áreas também foram criados, promovendo uma intensa batalha de informações, com o objetivo de, por um lado, defender ideias pouco fiéis à concepção de ciência, e, do outro, a busca da divulgação de informações cientificamente corretas ou associadas aos mecanismos consensuais pelos quais a ciência se desenvolve.

Nesta seara, questionamentos relacionados à educação científica e à própria educação midiática podem e devem ser feitos, na perspectiva de pensarmos ações educacionais futuras, que possibilitem o ensino sobre ciências e não apenas o ensino de ciências, entendendo-se este último como um conjunto de conteúdos isolados e fragmentados, organizados num currículo preditivo com foco em conhecimentos conceituais e, eventualmente, procedimentais (Hodson, 2014). 
Aspectos relacionados à epistemologia das ciências e questões voltadas à demarcação de diferentes campos de conhecimento - ainda que suscitem ampla discussão na comunidade acadêmica, nem sempre gerando consensos (Dupré, 1993; Grunbaum, 1984; Hansson, 2013, 2017; Rosenberg, 2012), são passíveis de serem incorporados à educação científica, de modo a desenvolver a capacidade de argumentação apropriada e, portanto, de considerar aspectos fundamentais do letramento científico (SANTOS 2007). Para tanto, avaliamos e temos como pressuposto que compreender como os diferentes discursos negacionistas se propagam é de suma importância para pensarmos como os mesmos podem ser enfrentados dentro de uma educação científica formal que englobe questões relativas à Natureza da Ciência (NdC).

Destacados tais aspectos iniciais, o presente trabalho tem por objetivo desenvolver uma análise de conteúdo de argumentos utilizados por defensores de desinformações, em resposta a textos de divulgação científica. Três aspectos principais serão então considerados: o tipo de negacionismo associado; o papel da hiperparticularização de conceitos; e; concepções de ciência que os argumentos carregam. Buscamos, com isso, tecer relações entre tais concepções, assim como tecer uma breve discussão sobre aspectos voltados à educação científica em tempos de acesso e circulação de desinformações. Para tanto, discutimos, a seguir, suportes teóricos relativos ao estudo da circulação de informação na mídia, inclusive no que diz respeito a sua associação ao negacionismo científico; da concepção de hiperparticularização dos conceitos e suas implicações; e de aspectos consensuais de NdC.

\section{Aportes teóricos: caracterização do negacionismo e das Fake News}

Devido ao contexto histórico no qual estamos inseridos, as notícias falsas (fake news) que circulam na mídia e nas redes sociais frequentemente versam sobre a pandemia da Covid-19. A desinformação a respeito dos conhecimentos científicos aumentou nos últimos anos, no Brasil; e notícias falsas a respeito de supostos tratamentos precoces, que poderiam evitar o falecimento pelo novo coronavírus e similares, foram difundidas quase sem controle nas redes sociais on-line (Recuero et al, 2020). De fato, os ambientes virtuais se tornaram locais propícios para a proliferação das fake news - notícias inteira ou parcialmente falsas, difundidas com a intenção deliberada de enganar.

Pariser (2012) chama as comunidades locais que se formam através do controle dos algoritmos de "bolha dos filtros" e discute como nossas visões e nossos conhecimentos prévios de mundo são fortalecidos dentro delas. Para manter o engajamento do usuário, os algoritmos selecionam e mostram os conteúdos com base naquilo que eles julgam saber sobre o usuário, de forma que as concepções que o usuário já possui são reforçadas. Além disso, as bolhas de filtro dão a impressão de que todos ao seu redor estão pensando a mesma coisa, reforçando visões de mundo.

Dentre os diversos tipos de notícias falsas que podem circular, Santaella (2019) reforça que é necessário saber separar os "níveis de malignidade". Para a autora, o tipo mais prejudicial são as "propagandas intencionalmente enganadoras com a finalidade de promover pontos de vista tendenciosos, quase sempre para alimentar causas e programas políticos" (2019: 35).

Quando falamos sobre um discurso negacionista, nos perguntamos o que, exatamente, é negado. Cohen (2001) categoriza três tipos de comportamento negacionista: o literal, o interpretativo e o implicatório. Destacamos que o autor descreve estados de negação que vão além do negacionismo científico, de forma que recorremos a suas ideias para falar sobre casos que envolvem o conhecimento científico, mas não se limitam a eles.

O primeiro caso, o literal, nega explicitamente o fato. A pessoa alega, por exemplo, que "isso não aconteceu", que "isso não é verdade"; ou recorre a discursos parecidos. Nega, por exemplo, que haja uma pandemia, ou que haja pessoas morrendo de covid-19. Cohen explica que alguns dos motivos para esse tipo de negação podem vir de uma ignorância genuína, de uma aversão deliberada de olhar para uma realidade insuportável demais para ser reconhecida, ou de mentiras e desinformações calculadas. 
O negacionista interpretativo não nega o fato, mas busca, por uma interpretação particular, um significado diferente para o ocorrido. Isto envolve discursos como "não sou alcóolatra, bebo socialmente", "não foi um assassinato, foi um acidente" etc. No nosso contexto, o negacionista interpretativo é aquele que fala, por exemplo, que "as pessoas estão morrendo, mas não é por covid-19". Para Cohen, esse tipo de negação vem de uma incapacidade genuína de compreender o que os fatos significam para as outras pessoas, de modo que a pessoa tenta se manter sem responsabilidades legais ou morais sobre o que acontece.

Por fim, o implicatório não tenta nem negar o fato, nem negar a sua interpretação convencional. O que é negado, ou minimizado, são as implicações morais, psicológicas ou políticas dos acontecimentos. Dado nosso contexto, o negacionista implicatório é aquele que repete discursos parecidos com "as pessoas estão morrendo de covid-19, mas não há nada que possa ser feito", ou "as pessoas iriam morrer de qualquer jeito". Cohen argumenta que esse tipo de negacionismo é o mais comum dentro do ambiente político, uma vez que é uma tentativa de evitar uma cobrança, moral ou psicológica, sobre as consequências dos fatos.

\section{A hiperparticularização dos conceitos}

Podemos compreender a aprendizagem em ciências como um movimento de busca fundamentada pela generalização. Praia, Pérez e Vilches (2007) apontam que uma das finalidades da ciência é vincular domínios aparentemente desconexos, procurando estabelecer leis e teorias que podem ser aplicadas em fenômenos diversos, buscando compreender as relações que manteriam entre si. Como sintetizam Pérez et al (2001), a busca aprofundada dos laços que ligariam campos que parecem desconexos é a forma mais correta de se fazer ciência, de modo a entender que fenômenos observados e/ou estudados são casos particulares de uma generalização maior.

Durante o processo de generalização, o que ocorre é a procura pelo invariável dentro de um conjunto de objetos e suas propriedades (Davidov, 1990). Como descreve Davidov (1990), durante o processo de aprendizagem, os estudantes se deparam com diversas coleções de impressões do mundo concreto, que servem como base para que eles possam realizar comparações com o objetivo de encontrar, dentro desses conjuntos, o que é invariável. Por meio desse procedimento, é possível, então, criar ideias abstratas capazes de generalizar o que há de único entre eles.

O encontro com o diverso é fundamental para a formação de uma abstração capaz de generalizar o conceito-chave que sintetiza o que há de essencial entre os fenômenos observados. Essa abstração generalizada é o germe (kernel) do conteúdo; e uma das principais dificuldades no processo de ensino e aprendizagem se dá quando os kernels não são compreendidos pelos estudantes (Davidov, como citado em Engeström, 1991).

Como descreve Engeström (1991), quando o conhecimento adquirido não é baseado na busca dessa abstração generalizada, os estudantes perdem a oportunidade de compreender e usar seus conhecimentos para deduzir, explicar e predizer os fenômenos concretos. O conhecimento se torna, então, encapsulado. Cria-se uma separação entre o conhecimento adquirido e o conhecimento "da vida real", pois os estudantes não percebem que o que se aprende (na escola) são casos particulares de uma generalização maior, a mesma generalização com que eles se deparam nos fenômenos encontrados fora da escola.

Consideramos que a não compreensão de que o conhecimento deve buscar pela generalização é o início de um problema que se tornou mais grave nos últimos anos, com o aumento da proliferação massiva de desinformações. Afinal muitas delas, difundidas nas mídias, possuem como característica o oposto da generalização. Assim, como muitas vezes a aprendizagem em ciências é falha, no que diz respeito à procura da generalização, quando o aprendiz se depara com problemas que não consegue compreender, não se produz um questionamento aprofundado sobre a questão, o que facilita a possibilidade de aderirse a uma explicação descontextualizada e particularizada (desinformação). 
Ao estudar o movimento terraplanista em uma comunidade on-line, Pivaro (2019) descreve o que chamou de hiperparticularização: a tendência dos membros da comunidade de utilizar conceitos científicos retirados de seu contexto original, sem a preocupação da busca pela generalização. Para defender o formato plano da terra, os usuários da comunidade recorrem a um conceito científico diferente a cada contexto diferente, sem a percepção de que um mesmo conceito poderia explicar os diferentes fenômenos percebidos. Essa extrema particularização das explicações pode induzir a conclusões contraditórias, quando os conceitos utilizados de forma descontextualizada são aprofundados em uma sequência de questionamentos linearizados.

A característica da hiperparticularização não é restrita unicamente à comunidade negacionista, manifestando-se em diversas comunidades online. Também podemos considerar o duplo uso do conhecimento científico como uma consequência do modo de pensar extremamente particularizado, uma vez que, deste modo, é possível, em determinada situação, acreditar no que diz a ciência; e, em outras, duvidar. A hiperparticularização permite que conceitos científicos sejam retirados de seus contextos originais e utilizados para explicar particularidades sem o compromisso de se pensar de forma aprofundada o tema em questão. Pensa-se só no problema imediato a ser resolvido, sem compromisso com a construção generalista do pensamento científico. O termo hiperparticularização foi utilizado para se opor ao que Santos e Mattos (2010) descrevem como a hipercontextualização: a generalização dos conceitos que se verifica quando o indivíduo percebe, a cada passo, os múltiplos contextos nos quais um mesmo conceito pode se articular.

\section{Natureza da Ciência (NdC)}

A Natureza da Ciência (NdC) tem sido amplamente discutida; e diferentes autores buscam construir uma epistemologia do conhecimento científico. Sob a óptica do ensino de ciência, investigam-se a compreensão, o desenvolvimento e a elaboração da ciência, desde aspectos metodológicos até as relações sociais, políticas e culturais que englobam o saber científico crítico e integrado com a sociedade. Assim, o ensino com foco em aspectos da $\mathrm{NdC}$ tem sido apontado como fundamental para a formação de alunos e professores, tendo aumentado significativamente o número de pesquisas reportadas (Moura 2014).

Segundo Bejarano et al (2019), um sujeito cientificamente alfabetizado, no nível da educação básica, é aquele que compreende a natureza da ciência: sua produção, avaliação e relações com o contexto, assim como a união de conhecimentos das diversas áreas da atividade científica, desde a elaboração de seus métodos e teorias, até seu caráter social e cultural.

Azevedo e Scarpa (2017) afirmam que alguns autores usam o termo NdC para descrever a natureza do conhecimento científico. Os pesquisadores em questão apontam ainda definições fundamentais para a $\mathrm{NdC}$, envolvendo características da investigação científica capazes de evidenciar como o conhecimento gerado influencia o indivíduo: os métodos; os padrões que orientam as pesquisas; como os cientistas interferem em um grupo social; e, por fim, como a ciência pode ser afetada pela sociedade. Ainda no contexto de conhecimento científico, autores apontam que a $\mathrm{NdC}$ auxilia o aluno na interpretação da Ciência contemporânea, possibilitando a compreensão das aplicações científicas no seu cotidiano, além de torná-lo um ser crítico capaz de somar em discussões públicas sobre o assunto e de avaliar os impactos que a Ciência pode produzir na sociedade (Barbosa, 2019).

Segundo Matthews (como citado em Bejarano et al, 2019: 968), um dos primeiros cientistas a falar sobre o assunto foi William Whewell, em 1854. Mas a NdC torna-se um tema relevante para o ensino, no âmbito internacional, por volta de 1989, quando Estados Unidos e Grã-Bretanha promovem reformas em seus currículos com o intuito de incorporar à educação básica discussões sobre a mutabilidade do conhecimento científico.

Apesar dos esforços, persiste uma percepção distorcida da ciência e do cientista, distante das práticas desenvolvidas em cenários reais, como apontam Azevedo e Scarpa (2017). Se dentro do ambiente 
acadêmico os estudantes não tiverem a oportunidade de conhecer, compreender e refletir sobre o processo de criação do conhecimento científico, o meio em que eles estão inseridos reforçará ideias inadequadas de ciência, construídas fora do ambiente escolar.

Alia-se a este fato o contexto atual, em que um conjunto imensurável de desinformações sobre a ciência circulam pelos canais midiáticos. Como discutimos anteriormente, compreender como tais desinformações carregam as concepções de $\mathrm{NdC}$ pode ser um caminho propício para o pensar em estratégias futuras de educação científica, assim como para a tomada de decisões que exigem avaliação crítica. Dessa maneira, a educação científica precisa atentar para o aprendizado de saberes conceituais e teóricos, a resolução de problemas, o processo de construção de conhecimento e a relação entre ciência, tecnologia, sociedade e ambiente (CTSA), além de garantir que o aluno possua capacidade de confrontar as questões que envolvem a sociedade e a ciência (Azevedo \& Scarpa, 2017).

Alguns autores defendem o uso de aspectos consensuais, que são atributos do conhecimento científico. Segundo Moura (2014), essas características podem ser definidas como: "Ciência mutável, dinâmica e com o objetivo de explicar os fenômenos naturais"; "Não existe um método científico universal"; "Teoria não é consequência de observação/experimentos e nem o contrário"; "A Ciência é influenciada pelo contexto social, cultural, político, etc., no qual ela é construída, não há neutralidade na construção da Ciência e do conhecimento científico" e; "Os cientistas usam imaginação, suas crenças, influências externas e outros recursos, para produzir Ciência".

Pérez et al (2001) apresentam um conjunto de sete aspectos, chamados de não consensuais, que deveriam ser evitados para que o saber científico não se afaste de suas características essenciais. Os autores ainda apontam que os aspectos não consensuais não devem ser tomados como um check list, por se tratar de uma primeira aproximação. Levando em conta essa advertência, utilizaremos esses aspectos em nossa análise, a saber: "Concepção empírico-indutivista e ateórica"; "Visão rígida (algorítmica, exata, infalível)"; "Visão aproblemática e ahistórica (dogmática e fechada)"; "Visão exclusivamente analítica"; "Visão acumulativa de crescimento linear"; "Visão individualista e elitista da ciência" e; "Visão socialmente neutra da ciência".

Salientamos nossa compreensão dos importantes debates oriundos das demarcações do campo da ciência e, mais recentemente, das pseudociências e das diferentes discussões sobre a temática da NdC. Entretanto, como estamos buscando articular outros dois níveis de análise (tipos de negacionismo e hiperparticularização dos conceitos), optamos, neste trabalho, pelo referencial dos aspectos não consensuais de Perez et al (2001).

\section{Metodologia}

Levando em conta os objetivos estabelecidos para a análise de conteúdo do discurso dos defensores de desinformações; e considerando, ainda, os referenciais já discutidos, assim como a importância da análise das desinformações para a educação científica, buscamos um percurso metodológico capaz de dar suporte à categorização dos argumentos utilizados pelos diferentes sujeitos desses discursos.

Os dados de análise surgiram de comentários realizados frente a textos de divulgação científica produzidos por um projeto de extensão denominado Sala V. Tal projeto tem como objetivo a criação de uma rede de divulgação científica entre escolas da rede básica de ensino de um município do interior de São Paulo, é coordenado por um docente de uma universidade estadual paulista e tem a participação de estudantes de graduação em diferentes cursos (Química, Física, Biologia, História, Linguística). O projeto surgiu em março de 2020, juntamente com a propagação do novo coronavírus no Brasil. Devido ao isolamento social provocado pela pandemia, não foi possível desenvolvê-lo junto às escolas da rede básica de ensino. A convite do projeto Blogs de Ciência, da mesma universidade, o projeto Sala V atuou na checagem de informações veiculadas no período da pandemia, produzindo materiais de divulgação na forma de textos, infográficos, vídeos e podcasts. 
Os textos, produzidos e publicados em um blog institucional, receberam inúmeros acessos e outros tantos comentários, de apoio, de dúvidas e de negação. Tal fato merece o devido destaque, pois demonstra que o texto "furou a bolha", chegando a públicos variados. Os comentários em resposta a esses textos foram analisados por meio da técnica de Análise de Conteúdo (AC) (Bardin, 1977) buscando, nos argumentos utilizados, aspectos do negacionismo científico, do papel da hiperparticularização dos conceitos na sustentação da desinformação e no surgimento de visões não consensuais de Natureza da Ciência. Nesta etapa, recorrendo à $\mathrm{AC}$, consideramos categorias a priori os mesmos conceitos: hiperparticularização, tipos de negacionismo e visões não consensuais. Na análise, procuramos tecer uma contraargumentação, mostrando os principais pontos de fragilidade dos argumentos e tentando identificar a origem dos comentários, no tocante ao uso dos conteúdos. Deste modo, de acordo com a AC, realizamos a análise considerando as seguintes categorias estabelecidas a priori:

Categoria 1 (C1): Aspectos da hiperparticularização: a tendência da utilização de conceitos científicos retirados de seu contexto original, sem a preocupação da busca pela generalização. As explicações tendem a conclusões contraditórias, em termos de conceitos científicos, ainda que os conceitos sejam, por vezes, empregados corretamente, em uma escala particular.

Categoria 2 (C2): Aspectos do tipo de negacionismo associado: o literal; o interpretativo; o implicatório.

Categoria 3 (C3): Aspectos não consensuais de Natureza da Ciência, de acordo com Perez (2001).

Para as categorias, procuramos unitarizar os comentários em Unidades de Contexto (UC) associadas a cada categoria. A depender da amplitude dos comentários, algumas Unidades de Registro (UR) foram estabelecidas, de modo a permitir uma maior compreensão da categorização.

Por fim, a articulação dos dados foi feita com base nessa análise e na ocorrência das categorias, juntamente com a discussão sobre o ensino de ciência e sobre ciência, tecendo-se relações com possibilidades para o letramento científico como possibilidade de enfrentamento à propagação de desinformações.

\section{Resultados e discussão}

Consideramos, em nossa análise, os comentários feitos em resposta a três textos produzidos no projeto. Os textos buscavam argumentar contrariamente a três Fake News que circularam no ano de 2020, com relação a tratamento ou cura da COVID-19. As Fake News em questão estavam relacionadas aos seguintes temas:

- Uso de uma mistura de desinfetante com ácido cítrico, na forma oral, no combate a diferentes doenças e distúrbios: em abril de 2020, foi noticiado em milhares de jornais que o então presidente dos EUA, Donald Trump, sugeriu um protocolo composto por injeção de desinfetante e luz solar para tratar pacientes da COVID-19. A ideia de que seria possível injetar produtos de desinfecção nas pessoas surgiu por meio de uma solução conhecida como Mineral Miracle Solution (MMS) ou solução mineral milagrosa (tradução livre).

- Uso de ozônio, na forma de gás ou solução por introdução retal, como tratamento contra a COVID-19. Em agosto de 2020, o prefeito de Itajaí - SC, realizou uma live em uma de suas redes sociais, afirmando que a cidade poderia começar um novo tratamento em pacientes com sintomas do novo coronavírus. O método era baseado em injetar ozônio por via retal durante dez dias, cada aplicação durando cerca de 2 a 3 minutos.

- Ingestão de alimentos com diferentes teores de acidez ( $\mathrm{pH}$ - potencial hidrogeniônico) como medida preventiva à infecção contra a COVID-19. No começo da pandemia surgiram inúmeras notícias sobre como a população deveria se proteger. Dentre as desinformações, circulou, via aplicativos de mensagens e redes sociais, que o combate ao novo coronavírus poderia ser 
realizado pelo consumo de alimentos mais alcalinos, apresentando-se uma relação de frutas que poderiam auxiliar na prevenção.

\section{Análise dos comentários}

Optamos por agrupar os comentários produzidos pelos pesquisados com base nas categorias já referidas, organizando-os em três quadros. A cada quadro se seguem a nossa interpretação e a justificativa da classificação, bem como a argumentação contrária. As Unidades de Registro seguem a codificação URCX. Y, onde X representa o número da categoria e Y o número da unidade. As Unidades de Contexto, por sua vez, estão codificadas como UCCW. Z, onde W representa o número da categoria e $\mathrm{Z}$ o número da unidade. Indicamos também o total de UC que foram identificadas, mas, devido ao pouco espaço disponível nos quadros, recorremos a um conjunto representativo para ilustrar a análise. Optamos por não interferir nos textos originais, transcrevendo-os tais como produzidos pelos sujeitos pesquisados.

O Quadro 1 ilustra as unidades de sentido associadas a C1.

Quadro 1: Aspectos associados à hiperparticularização dos conceitos.

CATEGORIA 1: Aspectos da hiperparticularização dos conhecimentos

\begin{tabular}{|c|c|}
\hline $\begin{array}{c}\text { Unidades de } \\
\text { Registro (UR) }\end{array}$ & Unidades de Contexto \\
\hline $\begin{array}{c}\text { URC1. } 1 \text { Utilização de } \\
\text { conceitos específicos (10 } \\
\text { UC) }\end{array}$ & $\begin{array}{l}\text { UCC1. } 1 \text { Esta substância é conhecida e utilizada de forma obrigatória para desinfecção de } \\
\text { sangue em bolsas p/ transfusão, desinfectar água, carnes, verduras, em vários países. } \\
\text { UCC1. } 2 . \text { É triste ler artigos assim, de gente que não sabe o que diz. Cloro existe na piscina, } \\
\text { mas ninguém derrete quando pula em uma, porque a proporção que foi jogado na água é } \\
\text { segura e aceitável pelo organismo humano. } \\
\text { UCC1. } 3 \text { Vale lembrar que nossa alimentação não tem o poder de mudar o PH sanguíneo, } \\
\text { porém alimentos alcalinizantes que não somente o limão colaboram para o organismo gaste } \\
\text { menos energia em manter o PH equilibrado e desempenhar com mais eficiência as funções } \\
\text { da manutenção celular bem como a de defesa (sistema imunológico). } \\
\text { UCC1. } 4 \text { Por exemplo, o limão contém o ácido cítrico que, no organismo humano, sofre } \\
\text { reação química, e torna-se um alcalinizante - neutraliza a acidez interna - estabilizando o } \\
\text { meio em pH alcalino. } \\
\text { UCC1. } 5 \text { Sabemos que o limão com glicose retira as células mortas da pele, e isto é inegável! } \\
\text { Eu penso que deveriam descer do Olimpo e pesquisar mais sobre o limão, porque partindo do } \\
\text { princípio que comprovadamente ele retira as células mortas da pele, colaborando para isso } \\
\text { com a renovação celular, é óbvio que a defesa da pele se fortalece contra a entrada de } \\
\text { organismos estranhos, pode parecer algo pequeno, mas não podemos desprezar, afinal a } \\
\text { guerra é feita de batalhas. }\end{array}$ \\
\hline $\begin{array}{l}\text { URC1. } 2 \text { Utilização de } \\
\text { conceitos gerais (6 UC) }\end{array}$ & $\begin{array}{l}\text { UCC1. } 6 \text { TODOS recebem os múltiplos benefícios desta terapia comprovada, que soluciona } \\
\text { mais de } 250 \text { doenças } \\
\text { UCC1. } 7 \text { Ozônio é usado na Russia desde } 1928 \text {, na Dinamarca e na Áustria é usado no } \\
\text { tratamento da água pública, reduzindo os casos de câncer de estômago e esôfago. } \\
\text { UCC1. } 8 \text { Foi esclarecido que era necessário fortalecer nosso sistema imunológico para } \\
\text { combater o vírus covid19. E que alguns alimentos contribuíam para isso, tais como limão, } \\
\text { corvina, própolis, gengibre etc. E que o limão também fortalecia o organismo com vitamina } \\
\text { c. Por outro lado, vi vídeo de um médico que esclarecia como a hidroxicloroquina aliada a } \\
\text { azitromicina combatia o vírus. Esclareceu que o vírus entra na célula e aloja nos ribossomos } \\
\text { onde tem um ph de } 6 \text { e multiplicava. Estes medicamentos alteravam o pH dos ribossomos } \\
\text { pouca coisa, mas suficiente para acabar com o vírus. }\end{array}$ \\
\hline
\end{tabular}

Fonte: Dados da pesquisa

Ao considerarmos a hiperparticularização, duas situações se evidenciam. Primeiramente, o uso de conceitos em situações específicas não generalizados para outras, não diretamente relacionadas (como 
podemos observar na URC1). As UCC1.1 e UCC1.2 ilustram extrapolações bastantes ingênuas relacionadas à aplicação das substâncias. $\mathrm{O}$ cloro (em diferentes formas químicas) é bastante utilizado em tratamento de água, eliminando micro-organismos. Por esta razão, o sujeito extrapola que, se o cloro mata micro-organismos, ao ingeri-lo ele irá matar o vírus em seu corpo. Essa conclusão desconsidera todo o conhecimento associado à biologia e à bioquímica. Pela mesma lógica, se ingerirmos veneno, teremos o mesmo resultado.

Em uma segunda linha de raciocínio, os comentários reportados nas UCC1.3 a UCC1.5, apesar de associarem os mecanismos de ação à complexidade do sistema vivo, carregam um conjunto de erros conceituais resultantes de uma extrapolação da ideia de que podemos mudar de forma rápida nosso organismo pela ingestão instantânea de um determinado substrato, como se pudéssemos mudar a acidez do corpo da mesma forma como alteramos a acidez de um copo de água. Estes pontos ilustram de forma clara o conceito da hiperparticularização, uma vez que deslocam um conhecimento sobre determinado tema para um contexto diferente, para chegar às mesmas conclusões (PIVARO, 2019).

Outro aspecto, ilustrado na URC1.2, é a generalização sem o apoio de conceitos científicos, a partir de dados aleatórios. Por exemplo, com base na afirmação de que o "Ozônio é usado na Rússia desde 1928, na Dinamarca e na Áustria é usado no tratamento da água pública, reduzindo os casos de câncer de estômago e esôfago", pouca ou nenhuma relação pode se estabelecer quanto ao uso de ozônio contra o coronavírus. O ozônio é usado no tratamento de água como alternativa ao cloro (ação antimicrobiana) e não como medicamento. Mas a associação que se faz é que seu uso combate o câncer, o que na verdade pode ser fruto de diferentes outras ações. Do mesmo modo, a UCC1.8 associa uma alimentação saudável e ao uso do limão o fortalecimento das defesas do organismo contra a COVID-19. Não se descarta que a alimentação adequada pode fortalecer o sistema imunológico; no entanto, nenhuma relação pode ser estabelecida entre o uso do limão e o combate ao coronavírus. Estas relações fragmentadas, lineares e descontextualizadas também apresentam paralelos com os aspectos vinculados ao tipo de negacionismo e com concepções não consensuais de $\mathrm{NdC}$, como discutiremos na sequência.

O Quadro 2 apresenta as UR e UC referentes à categoria 2. Além das tipologias referentes ao negacionismo, duas outras unidades de registro foram estabelecidas, uma vez que mesclam aspectos negacionistas diferentes.

Quadro 2: Aspectos do tipo de negacionismo associado

\begin{tabular}{|c|l|}
\hline \multicolumn{2}{|c|}{ CATEGORIA 2: Aspectos do tipo de Negacionismo } \\
\hline $\begin{array}{c}\text { Unidades de Registro } \\
\text { (UR) }\end{array}$ & \multicolumn{1}{|c|}{ Unidades de Contexto } \\
\hline URC2. 1 Literal (5 UC) & $\begin{array}{l}\text { UCC2. 1 e..ozônio é vida e não existem efeitos colaterais depois da utilização. Nenhuma } \\
\text { reação negativa! Só a cura mesmo. } \\
\text { UCC2. 2 Foi esclarecido que era necessário fortalecer nosso sistema emunologico para } \\
\text { combater o vírus covid19. E que alguns alimentos contribuíam para isso , tais como limão, } \\
\text { corvina, própolis, gengibre etc. E que o limão também fortalecia p organismo com vitamina c. } \\
\text { Por outro lado, vi. Vídeo de um médico que esclarecia como a hidroxicloroquina aliada a } \\
\text { azitromicina combatia o vírus. Esclareceu que o vírus entra na célula e aloja nós ribossomos } \\
\text { onde tem um ph de 6e multiplicava. Estes medicamentos alteravam o pH dos 121âncer121mos } \\
\text { pouca coisa, mas suficiente para acabar com o vírus. } \\
\text { UCC2. 3 Por isso que o limão mostra efeitos positivos contra todos os tipos de gripe. Ainda! } \\
\text { O covid-19 não se prolifera em meio ALCALINO... É ISSO! } \\
\text { UCC2. 4 eu acredito muito no limão, porque o limão, ao contrário do que diz o articulista, } \\
\text { segundo os nutricionistas, embora ácido, não participa do organismo com efeito acidificante e } \\
\text { sim como alcalinizante. Uma vez que, no estômago, o ácido cítrico contido no limão combina } \\
\text { com o sódio formando o citrato de sódio, excelente composto químico para alcalinizar as } \\
\text { células do organismo. E o vírus, de modo geral, não gosta de atacar o núcleo das células, onde } \\
\text { o pH não seja neutro. Não porque o 121ânce sofra efeito direto do nível do ph, mas sim porque }\end{array}$ \\
\hline
\end{tabular}




\begin{tabular}{|c|c|}
\hline & $\begin{array}{l}\text { pH ácido ou alcalino altera os trabalhos das enzimas citoplasmática, não permitindo que o } \\
\text { vírus faça a conversão do DNA dos cromossomos para RNA, conforma o projeto de qualquer } \\
\text { vírus. Motivo por que o limão tem mostrado efeitos positivos em todos os tipos de gripe }\end{array}$ \\
\hline $\begin{array}{l}\text { URC2. } 2 \text { interpretativo } \\
\text { (5 UC) }\end{array}$ & $\begin{array}{l}\text { UCC2. } 5 \text { Na forma MMS há resíduos, mas na forma CDS usa -se só o gás (dióxido de cloro) } \\
\text { misturado na água e na proporção indicada, nunca matou ninguém. } \\
\text { UCC2. } 6 \text { Não estou aconselhando o uso, mais sim, que o Governo faça estudo e não fique } \\
\text { ouvindo opiniões que não apresentem estudos. } \\
\text { UCC2. } 7 \text { Acredito que muitas informações são distorcidas, mais não podemos negar a } \\
\text { relevância do benefício do limão no auxílio ao combate do sarscov2. } \\
\text { UCC2. } 8 \text { Já que ninguém conhece o comportamento do civid-19 em nosso organismo, e nem } \\
\text { sabe como ele reage às drogas existentes, não devemos abrir mão do consumo das frutas ácidas } \\
\text { em momento algum. Tenho } 67 \text { anos e desde criança alimento limão laranja, abacaxi etc., e } \\
\text { graças a Deus, em toda minha existência não tive mais de meia dúzia de febre. Então que } \\
\text { continuemos ingerindo essas frutas. Conforme o ditado: para morrermos, basta estarmos vivos. } \\
\text { Ninguém é recolhido por Deus sem ter chegado a hora. }\end{array}$ \\
\hline $\begin{array}{l}\text { URC2. } 3 \text { Implicatório (3 } \\
\text { UC) }\end{array}$ & $\begin{array}{l}\text { UCC2. } 9 \text { Ocorre é que nenhuma indústria farmacêutica quer que a população saiba disso, } \\
\text { porque o MMS e o CDS são compostos por dois componentes que são obtidos de maneira } \\
\text { muito fácil por qualquer pessoa e isso impede que algum laboratório o patenteie. } \\
\text { UCC2. } 10 \text { Além disso, os médicos que ganham as suas devidas comissões da indústria } \\
\text { farmacêutica, bem como precisam que o paciente fique o maior tempo possível dependente } \\
\text { dele e de medicamentos químicos, não têm interesse de curar ninguém. Assim como está } \\
\text { ocorrendo com a hidroxicloroquina (em que o gasto total com o tratamento de um paciente até } \\
\text { sair da fase aguda sai por cerca } 40 \text { a } 60 \text { reais), outros medicamentos vendidos pelo mundo } \\
\text { custam de } 5 \text { a } 6 \text { mil dólares. }\end{array}$ \\
\hline $\begin{array}{l}\text { URC2. } 4 \text { Experiências } \\
\text { individualizadas (6 UC) }\end{array}$ & $\begin{array}{l}\text { UCC2. } 11 \text { Não é uma experimentação nova. Sua comprovação é MUITO antiga. Tive câncer } \\
\text { de colon sigmóide, retirei } 45 \text { centímetros do intestino grosso, e posteriormente a cirurgia, me } \\
\text { cuidei com ozonioterapia. TOTALMENTE CURADA após } 6 \text { anos de cirurgia. Me recusei a } \\
\text { fazer quimioterapia leve naquela época } \\
\text { UCC2. } 12 \text { Minha irmã pegou covid } 19 \text { e convivemos na mesma casa, eu não peguei a doença, } \\
\text { costumo consumir chá de limão com alho ( } 12 \text { de ph) tomo ele morno a noite essa receita é } \\
\text { antiga e previne muitas doenças. } \\
\text { UCC2. } 13 \text { Não vou me estender aqui tentando explicar detalhes técnicos, pois quem se arvorou } \\
\text { a escrever o texto acima é quem deveria ter pesquisado melhor, mas apenas saliento que não } \\
\text { existe nenhuma prova melhor para comprovar uma teoria científica do que a própria } \\
\text { experiência e eu posso garantir que usei, assim como minha esposa, além de dois amigos, } \\
\text { sendo que todos foram curados de suas doenças, sendo elas: malária, dengue e bactéria H- } \\
\text { pylori. Se duvidar, eu provo bebendo de novo na frente de qualquer um e vou mostrar que não } \\
\text { terei absolutamente nenhum efeito colateral e olhe que eu tomei a dose de um bezerro, segundo } \\
\text { os protocolos veterinários que testaram o produto em animais de engorda. } \\
\text { UCC2. } 14 \text { O ozônio tem sido usado "experimentalmente" na Italia. Veja os resultados... } \\
\text { enfim... ozônio sempre é renegado, sempre tem sua eficácia desconfiada, mas, o fato é que há } \\
\text { estudos contundentes desde o início do século } 20 . . . \text { sinceramente, pelo o que já me tratei e } \\
\text { resolveu, das coisas que vi em mais de } 10 \text { anos me tratando com ozônio, das pessoas que } \\
\text { ajudou, não sei pq ainda não faz parte da política pública de saúde. }\end{array}$ \\
\hline $\begin{array}{l}\text { URC2. } 5 \text { Pedido ou } \\
\text { fornecimento de fontes } \\
(4 \mathrm{UC})\end{array}$ & $\begin{array}{l}\text { UCC2. } 15 \text { Está sendo estudada na Suiça, cujo divulgador Andreas Kalcker se dispõe a enviar } \\
\text { todos os estudos científicos que o País interessado desejar. } \\
\text { Custo baratíssimo, qualquer farmácia pode fabricá-la. Aqui pode contatar: } \\
\text { https://andreaskalcker.com/. } \\
\text { UCC2. } 16 \text { Vejam meus Vídeos/aula sobre esse assunto, e vejam também no Google } \\
\text { Acadêmico o meu Artigo Científico publicado na Revista Científica ETC da Federal, o qual } \\
\text { foi indicado para Projeto de Lei na ALBa. } \\
\text { Endereço Eletrônico: } \\
\text { "Benefícios da água com pH alcalino. Saúde ou doença, você decide" } \\
\text { UCC2. } 17 \text { Já temos um estudo em andamento na Federal, sobre o bloqueio e desintegração do } \\
\text { novo Coronavírus, a partir do ambiente alcalino, já testado com pleno êxito com } 15 \text { voluntária } \\
\text { (de fé pública) infectados... }\end{array}$ \\
\hline
\end{tabular}


A URC2.1 nos mostra Ucs o que pode ser categorizado como um negacionismo literal: trata-se da negação explícita do próprio fato em questão. Nos comentários selecionados, é possível notar tentativas de justificar o uso de tratamentos alternativos para a COVID-19; para isso, nega-se o que dizem cientistas sobre o uso destes tratamentos, sem qualquer argumentação plausível para tanto.

As UCC2.1 e UCC2.3 mostram uma negação mais direta, por meio da expressão de que algo não existe/acontece. Podemos ver, na UCC2.1, que o internauta afirma que "não existem efeitos colaterais" para justificar a utilização do ozônio como tratamento para a COVID-19. De modo parecido, a UCC2.3 contém a afirmação do usuário de que o vírus da COVID-19 "não se prolifera em meio alcalino", para justificar o uso do limão no combate aos vírus, mesmo com o texto da divulgação científica informando que não se sabe quais são os níveis de $\mathrm{pH}$ suportados pelo novo coronavírus e, ainda, sendo o limão ácido, propriedade oposta à alcalina. Com esta afirmação, o usuário também se recusa a concordar que o limão não alcaliniza o sangue, uma vez que se trata de uma fruta ácida.

Já nas UCC2.2 e UCC2.4, o discurso negacionista não é tão direto. No entanto, também está presente de modo literal. Nelas, os usuários não negam explicitamente algo (não utilizam a expressão "isto não ocorre"), mas, de acordo com seus comentários, é possível denotar que se recusam a concordar com o conhecimento científico de que ingerir limão não auxilia no combate à COVID-19.

Na URC2.2, há UCs que mostram um negacionismo interpretativo, ou seja, não negam o fato, mas dão outra interpretação ou significado a ele. É comum, nesses casos, que as justificativas dadas pelos usuários tenham um formato como: "não estou negando o fato, mas ....".

Em nenhum dos registros os usuários negam que haja muita desinformação circulando, nem que ainda haja o que se descobrir a respeito do novo coronavírus. No entanto, apresentam objeções: mas o limão funciona; mas o governo precisa bancar seus próprios estudos e não confiar nos apresentados. Da mesma forma, em UCC2.5, o usuário não nega que haja uso de uma solução supostamente milagrosa, mas, afirma ele, ela nunca matou ninguém.

Já o negacionismo implicatório exposto na URC2.3 é aquele que nega as implicações do acontecimento. Vemos nas UC exemplos de discurso que colocam a culpa da proliferação do vírus e aumento da pandemia na indústria farmacêutica, que supostamente não quer que se invista em um tratamento barato para a população, como a hidroxicloroquina ou a ivermectina. Desta forma, exime-se de culpa os governantes que deveriam ter sido responsáveis por manter o controle da pandemia de forma mais adequada.

Nas URC2.4 e URC2.5 encontram-se os três tipos de negacionismos simultaneamente, mas com características e aspectos que justificam reuni-las em novas UR, para uma melhor discussão.

Na URC2.4 encontra-se o negacionismo advindo da experiência individualizada. Ou seja, as pessoas baseiam-se em experiências próprias; e acreditam que essa particularidade provocou uma consequência específica. Ao utilizar a experiência própria como forma de justificativa para algo, a pessoa recusa-se a aceitar outra explicação para o acontecido. Em UCC2.11, por exemplo, o usuário afirma que foi devido ao uso do ozônio que se curou de um câncer, mesmo tendo feito a cirurgia para retirar parte do intestino; em UCC2.12, a pessoa afirma que não pegou covid-19 pois costuma tomar chá de limão com alho. Mas não sabemos se a pessoa pegou e ficou assintomática, ou se realmente não pegou, seja por um simples acaso, seja como resultado do "tratamento".

Para a pessoa da UCC2.11, foi o ozônio que a curou, pois foi esta a sua experiência subjetiva; e, por isso, nega que o ozônio faça mal. No entanto, essa pessoa não leva em consideração que câncer e doenças respiratórias não são tratadas da mesma forma, nem possuem uma origem comum. Podemos traçar paralelos entre esse tipo de negacionismo e a hiperparticularização dos conceitos, uma vez que o fato do ozônio ter sido usado em um tratamento de câncer foi extrapolado para o tratamento de uma doença viral. Assim, o uso do ozônio foi descontextualizado e aplicado de forma arbitrária a uma outra doença, sem qualquer justificativa para o seu suposto funcionamento em um ou outro caso. Vemos em UCC2.13 
o mesmo fenômeno, de pessoas justificarem o uso ozônio contra a COVID-19 com o argumento de que ele nunca lhes fez mal.

Por fim, em URC2.5, o negacionismo é dirigido às fontes das pesquisas que afirmam a ineficácia do tratamento com limão ou da manipulação de pH, sob a alegação de que essas pesquisas não seriam confiáveis. Por não confiarem nestas pesquisas, em UCC2.16 e UCC2.17 os usuários afirmam terem eles próprios realizado pesquisas, para provar que estariam certos e as outras fontes de informações, erradas. Já em UCC2.15, a pessoa indica um outro divulgador que, supostamente, seria confiável.

Destacamos como, neste último UC, a pessoa fornece o site do suposto pesquisador, no qual, entretanto, o mesmo apenas afirma realizar pesquisas, sem citar nenhum artigo publicado verificado por pares nem indicar vínculo com qualquer universidade ou instituição de pesquisa. Vemos, aqui, que o conhecimento científico "oficial" (das universidades e centros de pesquisa) é negado, enquanto o conhecimento produzido por "pesquisadores alternativos" (que estariam denunciando aquilo que as grandes indústrias farmacêuticas e a academia não querem divulgar) é aceito sem qualquer questionamento.

Ao relacionarmos a URC2.4 e a URC2.5, percebemos que a experiência pessoal e a recusa do conhecimento científico "oficial" - aquele construído em conjunto, em que diferentes cientistas se comunicam e avaliam o trabalho de seus colegas, buscando o refinamento do conhecimento evidenciam que o entendimento sobre como se constrói o conhecimento científico é falho em parte expressiva da população. Constatamos que o conhecimento científico é negado para dar lugar a um outro, sem qualquer compromisso com a construção de procedimentos consensuados de observação, análise e verificação. Cada pessoa tem a "sua" versão sobre o que é verdade; ou escolhe, arbitrariamente, acreditar ou não nesta ou naquela fonte.

O Quadro 3 ilustra as UR e UC relacionadas a aspectos não consensuais da NdC, tais como destacados por Perez (2001).

Quadro 3: Aspectos não consensuais de Natureza da Ciência

CATEGORIA 3: Aspectos não consensuais de Natureza da Ciência

\begin{tabular}{|l|l|}
\hline $\begin{array}{l}\text { Unidades de } \\
\text { Registro (UR) }\end{array}$ & Unidades de Contexto (UC) \\
\hline $\begin{array}{l}\text { URC3. 1 Empírico } \\
\text { indutivista (2 UC) }\end{array}$ & $\begin{array}{l}\text { UCC3. 1 Gostaria que o Autor 1 e a Autora 2, antes de dar informações equivocadas para a } \\
\text { população, realizasse Testes com seres humanos (como eu venho realizando a quase } 10 \text { anos), } \\
\text { ao invés de se basear tão somente em Literaturas já ultrapassadas, estudadas nos cursos } \\
\text { (inclusive universitarios) em geral..!.!.!errados, } \\
\text { UCC3. 2 Levei para dois amigos internados com COVID respirando com auxílio de oxigênio. } \\
\text { disseram que após os primeiros } 10 \text { minutos, a melhora foi significativa. O aprelho de ozônio } \\
\text { que tenho é daqueles aberto com placas de....20 g p/h e ozoniza o ambiente. Meu protocolo } \\
\text { foi esse e deu certo. Uso sempre. Eu tinha um de 600 mg aquele com uma manguerinha. É } \\
\text { maravilhoso, melhor ainda se conseguir acoplar oxigênio puro medicinal para ozonizar e usar. } \\
\text { Tanto para respirar, ozonizar óleo, sub-cutânea para músculos. Pantorrilha e nervo radial. } \\
\text { Esses eu mesmo usei em mim. eu usei até na uretra há um 3 anos. Isso mesmo. Coloca } 30 \\
\text { segundos na uretra depois força pra sair. Resultado...tenho um filho rescêm nascido. }\end{array}$ \\
\hline $\begin{array}{l}\text { URC3. 2 } \\
\text { Exclusivamente } \\
\text { analítica (2 UC) }\end{array}$ & $\begin{array}{l}\text { UCC3. 3 Já temos um estudo em andamento na Federal, sobre o bloqueio e desintegração do } \\
\text { novo Coronavírus, a partir do ambiente alcalino, já testado com pleno êxito com } 15 \text { voluntária } \\
\text { (de fé pública) infectados... } \\
\text { UCC3. 4 Vejam meus Vídeos/aula sobre esse assunto, e vejam também no Google Acadêmico } \\
\text { o meu Artigo Científico publicado na Revista Científica ETC da Federal, o qual foi indicado } \\
\text { para Projeto de Lei na ALBa. }\end{array}$ \\
\hline
\end{tabular}


URC3. 3 Individualista e elitista (5 UC)

UCC3. 5 Uma médica e professora de medicina chinesa falou em palestras sobre o poder do alho e do limão contra a covid e ela foi presa por isso, então acredito que deve haver um fundo de verdade nisso.

UCC3. 6 Respeito os autores, mas minha médica, Dra. Dayana Hannemam, clínica, ortomolecular, fez diversas especializações no exterior e com o Dr. Lair Ribeiro (médico que já deu aulas em Harvard)

UCC3. 7 Também sigo Lair Ribeiro, meu gurú. Ah e passei a dormir melhor com Ozônio desde 2016

UCC3. 8 O trabalho vosso é sério, porém pesquisem doutores como lair ribeiro entre outros e irão se surpreender. Obrigado

UCC3. 9 Verificar sobre essa substância, cujo estudo clínico em humanos, encerram em 1/6/2020, na Colômbia (https://patentimages.storage.googleapis.com/f0/8f/9b/4356d4bff1c967/ES2518368T3.pdf). Os estudos em andamento constatam atualmente uma efetividade de $97 \%$. Alguns links para subsídio: https://www.docdroid.net/wIPxtU5/clo2-covid19-general2eng-pdf; https://andreaskalcker.com/documentos-cientificos/;

https://patentimages.storage.googleapis.com/f0/8f/9b/4356d4bff1c967/ES2518368T3.pdf.

UCC3. 10 Ocorre que nenhuma indústria farmacêutica quer que a população saiba disso, porque o MMS e o CDS são compostos por dois componentes que são obtidos de maneira muito fácil por qualquer pessoa e isso impede que algum laboratório o patenteie.

UCC3. $11 \mathrm{O}$ autor do comentário apresenta a argumentação de que o MMS e alguns medicamentos que fizeram parte de inúmeras fake news sobre o novo coronavírus, não são

URC3. 4 Socialmente Neutra (2 UC) divulgados porque a indústria farmacêutica não deseja ou até mesmo o governo, ainda afirmando que os compostos ajudam no tratamento de bactérias, vírus e fungos, o que realmente acontece em determinados casos, mas não por meio de ingestão, o cloro mesmo é muito utilizado para desinfecção de ambientes, mas não deve ser ingerido, pois apresenta inúmeros riscos à saúde. Finalizando com a sugestão de um único médico, como se a ciência fosse feita por apenas um homem e por sua opinião, sem ter a existência de pesquisas que refutem algumas informações.

UCC3. 12 Além disso, os médicos que ganham as suas devidas comissões da indústria farmacêutica, bem como precisam que o paciente fique o maior tempo possível dependente dele e de medicamentos químicos, não têm interesse de curar ninguém. Assim como está ocorrendo com a hidroxicloroquina (em que o gasto total com o tratamento de um paciente até sair da fase aguda sai por cerca 40 a 60 reais), outros medicamentos vendidos pelo mundo custam de 5 a 6 mil dólares. Pergunto agora ao autor desse indigitado pasquim: em qual caso

URC3. 5 apelo social/econômico (2 UC) você se encaixa?

UCC3. 13 Eu só lamento o entrave acadêmico, governamental, e da indústria farmacêutica. que acaba impedindo de pessoas serem tratadas com cloroquina, ivermectina, mms entre outros medicamentos que já é comprovado que combatem todo tipo de vírus bactérias fungos. eu sou testemunha viva do uso do mms e indico a outros não só o mms como ivermectina e outros mais.

Fonte: Dados da pesquisa

Apesar da menor quantidade de unidades de contexto, é possível estabelecer algumas relações entre os comentários e alguns aspectos da $\mathrm{NdC}$, bem como articular as concepções em jogo ao tipo de negacionismo e à hiperparticularização. Um aspecto que destacamos para discussão é a interpretação inadequada das fontes.

A cobrança de fontes tornou-se comum tanto a divulgadores científicos quanto a negacionistas, o que poderia indicar um aspecto positivo, no que diz respeito ao entendimento sobre a construção do conhecimento científico. Em alguns casos, no entanto, as fontes são inúteis ou são interpretadas de maneira equivocada. Nos exemplos acima, os estudos reportam apenas desinfecção de ambientes externos, e não a desinfecção interna por ingestão direta. As fontes são encaradas como uma forma de gerar credibilidade por meio da "autoridade científica", aspecto relacionado à ideia de uma ciência elitista e de verdade absoluta. Todavia, as visões não consensuais representam e fortalecem a distorção do caráter científico como perspectiva certificativa da produção de conhecimento.

Nota-se, na UCC3.9, que um usuário fornece diversos links de supostos estudos e testemunhos, relativos a uma substância que combateria o novo coronavírus. A recusa deste usuário em aceitar o conhecimento 
científico "oficial" o leva à procura de uma alternativa que, aparentemente, também se basearia no conhecimento científico. $\mathrm{O}$ usuário procura por fontes por entender que é preciso recorrer a elas para sustentar uma afirmação científica. No entanto, a recusa do conhecimento científico construído coletivamente (o "oficial"), assim como a descrença de que estes coletivos estariam buscando pelo refinamento do conhecimento, levam o usuário a procurar individualmente por caminhos e soluções avessos aos procedimentos científicos reconhecidos.

A UCC3.9 pertence à URC3.3, que indica uma visão não consensual da NdC como individualista e elitista. O usuário da UCC3.9 recusa a ciência construída coletiva e consensualmente, apostando em que pessoas isoladas podem, pontualmente, construir um conhecimento científico sem precisar conversar e articular suas ideias com outros cientistas. Trata-se de uma outra maneira de se hiperparticulalizar a construção do conhecimento científico, pois fontes não validadas pela comunidade acadêmica são percebidas, pontualmente, como confiáveis, em determinado assunto. Esta discussão também se articula com o que destacamos sobre a relação entre as URC2.4 e URC2.5, na sessão anterior, o que indica que o negacionismo científico e as visões não consensuais sobre a $\mathrm{NdC}$ possuem pontos em comum entre as pessoas que praticam estes discursos.

Com o objetivo de ilustrar o uso inadequado ou restrito das fontes, destacamos a análise de uma das fontes citadas no comentário. $\mathrm{O}$ texto $\mathrm{em}_{\mathrm{jog}}{ }^{1}$ diz respeito a um pedido de uso do dióxido de cloro vaporizado no ar em concentrações de no máximo $0,1 \mathrm{ppm}$. O texto de divulgação científica, no entanto, se refere ao uso da substância administrada diretamente no organismo, e não vaporizada no ar, algo bastante diferente, porque, além da concentração de uma solução caseira ser maior do que 0,1 ppm, sua administração direta acarretará um maior contato da substância com partes do organismo.

O uso para "desinfecção de sangue em bolsas p/ transfusão, desinfectar água, carnes, verduras, em vários países", citado em UCC3.9, é um uso externo. Ou seja, é o mesmo que passar um agente desinfetante em um alimento para depois consumi-lo. No outro texto indicado pelo internauta ${ }^{2}$, os autores sugerem uma proposta de teste ainda sem resultados. Citam vários trabalhos feitos na mesma linha, mas que, em grande parte, se referem à desinfecção externa. Quando administrados, produzem efeitos colaterais; e embora apoiem alguma premissa relativa ao uso, o estudo apresenta um teste para apenas 20 pacientes. Apesar dessa insuficiência de representatividade, o estudo é utilizado como base para a generalização de um possível conhecimento científico, construído, no entanto, isoladamente.

Tal ponto é interessante porque vai além das discussões propostas por Perez (2001). A ideia de ciência individualista e elitista, sugerida pelo autor, se refere à percepção de que a produção científica só é possível quando realizada por indivíduos de uma classe favorecida intelectual e financeiramente, atuando isoladamente. Os comentários expandem essa noção negativamente, pois mantêm a ideia de isolamento, mas que agora pode ser de qualquer pessoa, inclusive atuando sem qualquer perspectiva metodológica para a realização dos procedimentos. As fontes tornam-se, portanto, qualquer experiência realizada, com ou sem rigor metodológico.

Associando tais visões aos tipos de negacionismo, consideramos que esses comentários se enquadram, em maior escala, no interpretativo. Por vezes, vemos que não se nega o fato de que o produto faz mal. Mas há a tentativa de refutar, utilizando uma "contraciência" falha e com dados alterados ou interpretados de forma a comprovar uma posição, o que, novamente reforça não só uma visão exclusivamente analítica, mas também aproblemática e a-histórica (dogmática e fechada) do conhecimento científico.

O comentário todo tem um caráter exclusivamente analítico, de simplificação e fragmentação da ciência, transformando as pesquisas que descredibilizam o tratamento como uma parte que pode ser ignorada. $\mathrm{O}$ usuário inicia sua argumentação com uma afirmação que sugere que o contato externo com cloro pode

\footnotetext{
${ }^{1}$ Disponível em:

https://patentimages.storage.googleapis.com/f0/8f/9b/4356d4bff1c967/ES2518368T3.pdf. Acesso em: 24/01/2022.

${ }^{2}$ Disponível em: https://www.docdroid.net/wIPxtU5/clo2-covid19-general2eng-pdf. Acesso em: 24/01/2022.
} 
ser equiparado à sua ingestão pelo homem. Na segunda parte de sua argumentação, o autor do comentário aponta que para provar algo é necessário a experimentação, assim se oferecendo para ingerir a solução. Omite, entretanto, as pesquisas e análises que já comprovaram os numerosos malefícios que o consumo do MMS causa ao organismo. Outro raciocínio errôneo é a comparação do organismo humano com o de animais de engorda, que possuem um sistema digestivo completamente diferente.

Destacamos, ainda, na URC3.5, um apelo socioeconômico, com a afirmação de que a indústria farmacêutica não permite a divulgação do produto porque é de baixo custo, esquecendo, no entanto, que o MMS não é um medicamento; para que assim fosse considerado, ele deveria tratar algo, como afirma a Organização Mundial da Saúde. Destaca-se, ainda, o caráter pejorativo associado à "química", quando o comentarista aponta dependência média e de medicamentos químicos, esquecendo que o cloro também é uma substância química, e que se a solução fosse um medicamento — o que já foi constatado que não é - também se trataria de uma solução química.

\section{Considerações finais}

Por meio da análise dos dados originários dos comentários produzidos em resposta aos textos de divulgação veiculados por um blog institucional, retomamos, nesta seção, nossos objetivos de discutir as relações associadas a nossos referenciais teórico-metodológicos e de tecer uma breve discussão sobre suas possibilidades para a educação científica.

A Figura 1 ilustra a conexão entre as categorias analisadas.

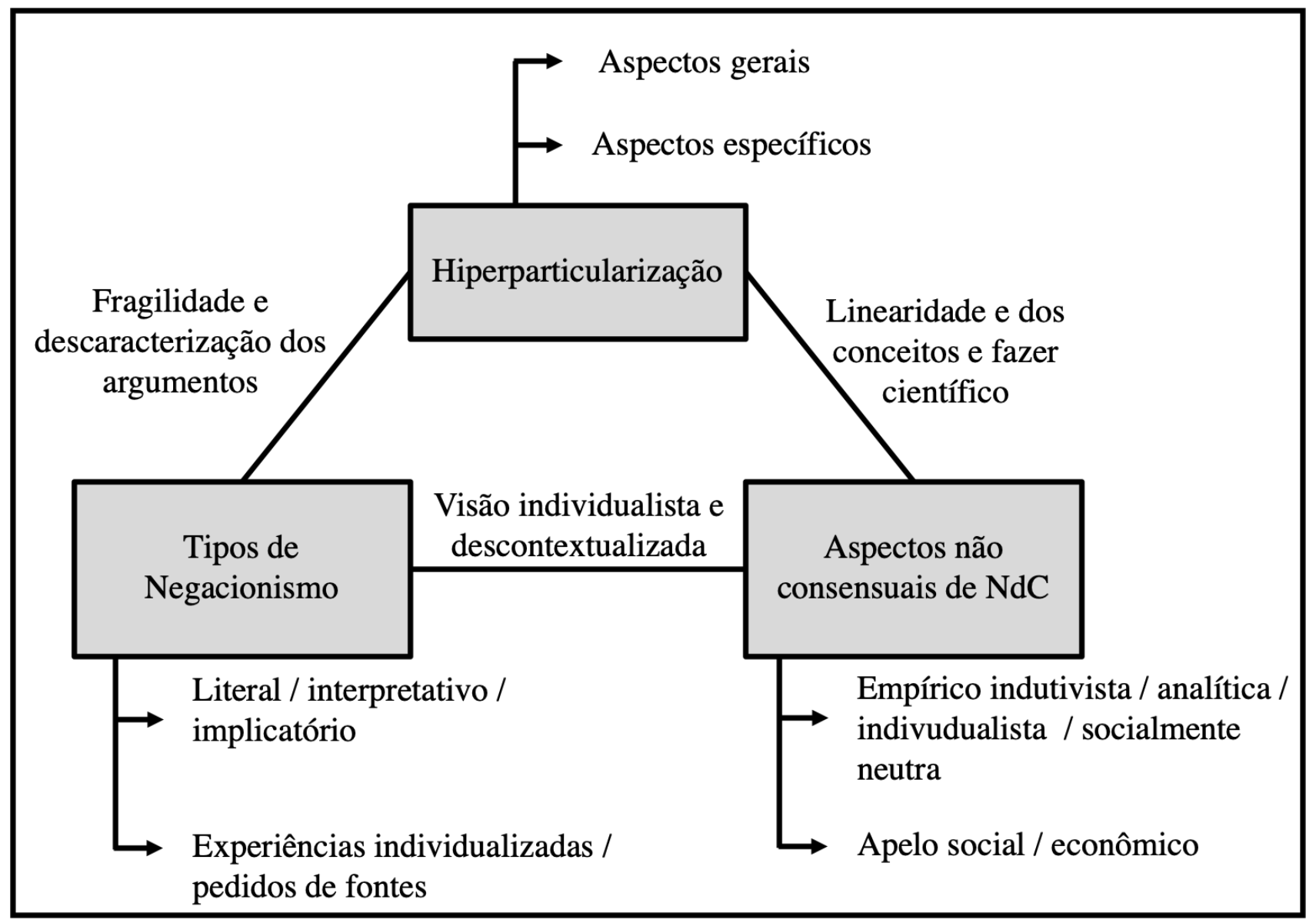

Figura 1: Relação entre as categorias analisadas, com base na análise de conteúdo dos dados. Fonte: os autores.

Podemos estabelecer que há relações entre os tópicos referentes a hiperparticularização, aos tipos de negacionismo e às visões não consensuais de $\mathrm{NdC}$, uma vez que, na análise das unidades de registro e contexto, foi possível notar justaposição de ideias próprias de cada referencial. Destacamos, na figura, que a fragilidade e a descaracterização dos argumentos utilizados pelos usuários têm forte relação com 
a natureza do negacionismo. Por vezes, a hiperparticularização dos conceitos é a causa do próprio argumento negacionista.

Ao considerarmos a perspectiva da educação científica sob a ótica do letramento científico, cujas ideias alinham-se ao uso contextual de diferentes linguagens e conceitos apropriados a um cenário de interpretação social da ciência, particularizar um conceito caminha de forma contrária à criação de argumentos sociocientíficos sólidos (SANTOS 2007). É nesse sentido que tecemos a reflexão de como a educação formal pode, atuando em termos de discussões menos fragmentadas de conceitos, contribuir para debates mais amplos. Não há, aqui, a intenção de prescrever meios pelos quais se deva realizar o ensino das diferentes áreas, mas concordamos com a ideia de que o ensino de conceitos deve perpassar a perspectiva conceitual e procedimental, associando-se cada vez mais à perspectiva atitudinal. Os caminhos para tal podem ser diversos.

Além disso, tanto a hiperparticularização quanto os tipos de negacionismo influenciam e são influenciados pelos aspectos não consensuais de $\mathrm{NdC}$. Destacamos que o referencial para os aspectos não consensuais pode ter gerado dificuldades para a análise, por carregar concepções de debates ainda muito recentes. Entretanto, aspectos interessantes emergem, como a ideia de que o rigor elitista das ciências, na visão não consensual, passa agora a ser refutado pelo negacionismo por meio de uma ausência de rigor no fazer ciência, carregando diversas concepções alternativas avessas a refutações, aspecto contrário a concepções clássicas do fazer científico como a de Popper (2014). Salientamos, também, que é possível encontrar elementos de interlocução, principalmente voltados à linearidade da produção científica e da visão descontextualizada. Retomando as ideias de Hodson (2014), defendidas também por outros autores, mas que ainda carregam dificuldades, tanto na formação de professores como no próprio trabalho com o ensino e a aprendizagem, o ensino de ciências deve incorporar também o ensino sobre as ciências, suas epistemologias específicas e, principalmente, as didáticas relacionadas a estas últimas.

Finalizamos o trabalho salientando que não é possível afirmar que os comentários analisados sejam representativos de um conjunto maior da população. Não obstante, a rede de circulação de desinformações é ampla e tem sido utilizada como estratégia política e de manipulação e, portanto, análises como a realizada neste trabalho são necessárias (e perfeitamente passíveis de aprimoramentos), para que possamos compreender quais são os artifícios utilizados por determinados grupos, pensando em perspectivas de formação de estudantes críticos para o enfrentamento das situações. Reconhecemos que o espaço virtual, como lugar de educação não formal, tem sido frequentemente utilizado como espaço de desinformação e que, quando se propõe a promover informações adequadas, carrega ideologias e interesses. A educação formal precisa, portanto, incorporar novos caminhos para a formação crítica.

\section{Referências}

Barbora, F \& Aires, J. (2019) Aspectos consensuais da Natureza da Ciência e suas implicações para o ensino de química. Revista Debates em Ensino de Química. 5(1), 26-44.

Bardin, L. (1997) Análise de conteúdo. Lisboa: Edições 70, 1977.

Bejarano, N; Aduriz-Bravo, A \& Bonfim, C. (2019) Natureza da Ciência (NOS): para além do consenso. Ciência \& Educação. 25(4), 967-982.

Cohen, S. (2001) States of Denial : Knowing about Atrocities and Suffering. Cambridge, UK: Polity Press.

Davidov, V, V. (1990) Types of Generalization in Instruction: Logical and Psychological Problems in the Structuring of School Curricula. Soviet Studies in Mathematics Education Volume 2. Translated by Joan Teller. 
Dupré, J. (1993) The Disorder of Things: Metaphysical Foundations of the Disunity of Science. Londres: Harvard University Press.

Engeström, Y. (1991) NON SCOLAE SED VITAE DZSCZMUS: Toward overcoming the encapsulation of school learning. Learning and Instruction. 1, 243-259.

Grunbaum, A. (1984) The foundations of psychoanalysis: A philosophical critique. Berkeley: University of California Press.

Hansson, S. O. (2013) Defining pseudoscience and science. In: Pigliucci, M. \& Boundry, M. (ed.). Philosophy of Pseudoscience: Reconsidering the Demarcation Problem (pp. 61-77). Chicago \& Londres: The University of Chicago Press.

Hansson, S. O. (2017) Science and Pseudo-Science. In: Zalta, E. N. (ed.). The Stanford Encyclopedia of Philosophy. Stanford: Metaphysics Research Lab, Stanford University. Recuperado de: https://plato.stanford.edu/archives/sum2017/entries/pseudo-science/

Hodson, D. (2014) Learning Science, Learning about Science, Doing Science: Different goals demand different learning methods. International Journal of Science Education, 36 (15), 2534-2553.

Leite, J. C. (2014) Controvérsias científicas ou negação da ciência? A agnotologia e a ciência do clima. Scientia Studia, 12(1), 179-89.

Mortimer, E. F. (1996) Construtivismo, mudança conceitual e ensino de ciências: para onde vamos? Investigações em Ensino de Ciências, 1(1), 20-39.

Moura, B. (2014) A natureza da Ciência e qual sua relação com a História e Filosofia da Ciência? Revista Brasileira de História da Ciência. 7(1) 32-46.

Pariser, E. (2012) O filtro invisível: o que a internet está escondendo de você. Editora SchwarczCompanhia das Letras.

Pérez, D. G ; Montoro, I. F ; Alís, J. C ; Cachapuz, A. \& Praia. P. (2001). Para uma imagem não deformada do trabalho científico. Ciência \& Educação, 7(2), 125-153. https://doi.org/10.1590/S1516$\underline{73132001000200001}$

Pivaro, G. F. (2019) A crença numa Terra plana e os ambientes virtuais: identificando relações e construções de conhecimento. In: Atas do XII Encontro Nacional de Pesquisa em Educação em Ciências, (pp. 1-7). Recuperado de http://abrapecnet.org.br/enpec/xii-enpec/anais/resumos/1/R2128-1.pdf

Pivaro, G. F \& Girotto Jr, G. (2020) O ataque organizado à ciência como forma de manipulação: do aquecimento global ao coronavírus. Caderno Brasileiro de Ensino de Física, 37(3), 1074-1098

Popper, K. Conjectures, and refutations: The growth of scientific knowledge. $2^{\mathrm{a}}$ ed. Nova Iorque: Routledge, 2014.

Praia, J, Pérez, D. G \& Vilches, A. (2007) O papel da natureza da ciência na educação para a cidadania. Ciência e Educação, 13(2), 141-156

Recuero, R; Soares, F. B.; Vinhas, O.; Volcan, T.; Zago, G.; Stumpf, E. M.; ... \& Sodré, G. (2020) Desinformação, Mídia Social e COVID-19 no Brasil: Relatório, resultados e estratégias de combate. (Relatório de Pesquisa). Recuperado de https://wp.ufpel.edu.br/midiars/files/2021/05/Desinformac\%CC\%A7a\%CC\%83o-covid-midiars-20211.pdf 
Reusing, L.; Wachowicz, M. (2019) A agnotologia no processo de conhecimento na biotecnologia. P2P E INOVAÇÃO, 6(1), 35-48. https://doi.org/10.21721/p2p.2019v6n1.p35-48

Rosenberg, A. (2012) Philosophy of Science: A contemporary Introduction. (3a ed.) Nova Iorque: Routledge.

Santaella, L. (2019) A Pós-Verdade é verdadeira ou falsa? Barueri, SP: Estação das Letras e Cores.

Santos, F. P. P \& Mattos, C. R. de. (2009) Generalização e Contextualização no Ensino de Ciências. In: VII Encontro Nacional de Pesquisa em Ensino de Ciências. (pp. 1-12) Florianópolis-SC.

Santos, W. L. P. (2007) Educação científica na perspectiva de letramento como prática social: funções, princípios e desafios. Revista Brasileira de Educação, 12(36), 474-550. 